LIAMES, Campinas, SP, v. 20, 1-17, e020017, 2020

\title{
Alinhamento morfossintático em Matis (Pano) ${ }^{1}$
}

\author{
Raphael Augusto Oliveira Barbosa \\ Universidade de São Paulo, Brasil \\ Fundação de Amparo à Pesquisa do Estado de São Paulo \\ https://orcid.org/0000-0001-7719-6169
}

\begin{abstract}
This article describes the morphosyntactic alignment in Matis, a language of the Panoan family, spoken in the Javari Valley indigenous territory, western region of the state of Amazonas, Brazil. Studies about the Matis language have been published since the beginning of the 21st century, with analysis of the morphosyntactic alignment restricted to morphological aspects of the clause. Based on the results of these studies and on the description of primary data, this paper proposes the systematized description of the morphosyntactic alignment through the functional and textual analysis of case-marking aspects. The analysis is based on the principles of Typological Functional Linguistics, through the description of data obtained in elicitation sessions and extracted from narratives collected in fieldwork. The results of the morphological analysis indicate the relation of noun categories between morphosyntactic alignment and the ergativity in the case syncretism. In the syntactic analysis, the functional system of the morphosyntactic alignment is the main condition for the interaction between the syntactic ergativity and the participant agreement. It is hoped that the results and conclusions presented in this paper contribute to the understanding on the Matis transitivity systems, as participant agreement and morphosyntactic alignment.

KeYwORDs: Case-marking; Split ergativity; Case syncretism; Participant agreement; Amazonian languages.
\end{abstract}

Resumo: Este artigo descreve o alinhamento morfossintático em matis, língua da família Pano, falada na terra indígena Vale do Javari, região oeste do estado do Amazonas, Brasil. Estudos sobre essa língua têm sido realizados desde o início do século XXI, com análises do alinhamento morfossintático restritas a aspectos morfológicos da oração. Baseado nos resultados desses estudos e na descrição de dados primários da língua matis, o presente trabalho propõe a descrição sistematizada do alinhamento morfossintático, por meio da análise funcional e textual da marcação de caso. A abordagem teórico-metodológica tem como base os princípios da Linguística Tipológica Funcional, com a análise realizada por meio da descrição de dados obtidos em sessões de elicitação e extraídos de narrativas coletadas em trabalho de campo. Os resultados da análise morfológica indicam a relação de categorias nominais entre o alinhamento morfossintático e a ergatividade no sincretismo de casos. Na análise sintática, o sistema funcional do alinhamento morfossintático define a interação gramatical da

${ }^{1}$ Agradeço à FAPESP - Fundação de Amparo à Pesquisa do Estado de São Paulo (Processo no 2017/09686-9) pelo apoio financeiro essencial para realização deste estudo, desenvolvido no Programa de Pós-Doutorado da Faculdade de Filosofia, Letras e Ciências Humanas da Universidade de São Paulo. Meus agradecimentos a Bëux Matis, Kuinin Matis, Makë Matis, e Tupa Matis, pela colaboração na pesquisa com a coleta e processamento dos dados. Agradeço também aos pareceristas pelos comentários e sugestões de aprimoramentos. Quaisquer desvios de interpretação ou erros de análise são de minha responsabilidade.

DOI: http://dx.doi.org/10.20396/liames.v20i0.8661192 


\section{BARbOSA - Alinhamento morfossintático em Matis (Pano)}

ergatividade sintática e a concordância de participante. Espera-se que os resultados e conclusões apresentados neste artigo contribuam na compreensão dos sistemas de transitividade da língua matis, como a concordância de participante e o alinhamento morfossintático.

Palavras-chave: Marcação de caso; Ergatividade cindida; Sincretismo de casos; Concordância; Línguas amazônicas.

\section{Introdução}

Aspectos funcionais de sistemas de alinhamento morfossintático revelam propriedades relevantes na compreensão do funcionamento cognitivo e textual da linguagem humana. O alinhamento morfossintático da língua matis (família Pano) é descrito como ergativoabsolutivo, com cisão na categoria do plural de pronomes pessoais. Com base nos resultados apresentados nessas descrições, o objetivo deste artigo é descrever o sistema de alinhamento morfossintático em matis, a fim de analisar a relação gramatical de categorias nominais e verbais. A descrição segue os princípios teóricos de correntes funcionalistas, sobre de linha tipológica e sistêmico-funcional, mediante a análise de dados obtidos por elicitação e provindos de textos narrativos.

Os Matis vivem na Terra Indígena Vale do Javari (aldeias Paraíso, Tawaya e Kuraya), e na cidade de Atalaia do Norte, oeste do estado do Amazonas. Nas aldeias, apenas a língua matis é falada; na cidade, os falantes se comunicam na língua nativa; e, em contextos comerciais e educacionais, na língua portuguesa. Atualmente, de acordo com entrevistas realizadas durante trabalho de campo, cerca da metade da população matis vive em Atalaia do Norte. Conforme o Instituto Socioambiental (ISA 2014), por meio de dados do SIASI/SESAI, ${ }^{2}$ a população contava em 2014 com aproximadamente 460 indivíduos, o que caracteriza a língua como ameaçada de extinção.

As seguintes subseções desta introdução descrevem os materiais e os aspectos metodológicos utilizados no trabalho, seguidos das características tipológicas da língua matis. Na seção seguinte, apresento a análise dos aspectos morfológicos do sistema de alinhamento e do sincretismo de casos. Em seguida, são analisados os aspectos sintáticos do alinhamento e a relação de argumentos verbais com processos de concordância. Por fim, a conclusão e as referências bibliográficas complementam o trabalho.

\subsection{Materiais e método}

Aspectos antropológicos do povo matis foram estudados por Arisi (2007, 2011, 2012, 2017) e da gramática da língua, por Barbosa (2018; ms), Ferreira R. (2001, 2005, 2012, 2017) e Ferreira V. (2000, 2005), cujos estudos serviram de base na metodologia da coleta e análise dos dados deste estudo. Esses dados foram coletados em 2018 e 2019, na cidade de Atalaia do Norte (região oeste do estado do Amazonas), com falantes nativos da língua. Os princípios metodológicos do quadro teórico assumidos no trabalho de campo seguem os princípios funcionais e colaborativos na coleta e análise textual, apresentados em Bowern (2008), Chelliah e Reuse (2011) e Crowley (2007).

${ }^{2}$ SIASI: Sistema de Informação da Atenção à Saúde Indígena; SESAI: Secretaria Especial de Saúde Indígena. 
O trabalho de Ferreira R. (2012) apresenta a descrição do inventário dos marcadores de referência-alternada na língua matis. A respeito desse sistema, Ferreira R. (2017) descreve a concordância adverbial de sujeitos na mesma oração e a concordância verbal de argumentos entre orações. $\mathrm{O}$ autor propõe, conforme assumido neste estudo, que esses morfemas constituem o sistema de concordância de participante (voltado para a distinção da função do sintagma nominal), diferente da concordância de transitividade (voltado para a distinção da valência verbal).

O sistema de alinhamento morfossintático da língua matis é descrito conforme os princípios analíticos da Gramática Sistêmico Funcional (Halliday e Matthiessen 2014). Nessa abordagem de base tipológica, a definição de língua como rede de sistemas semióticos vai ao encontro da análise dos processos que compõem o alinhamento morfossintático. Nesse sentido, a formação de palavras e a estrutura gramatical das orações são processos que levam em conta a organização do componente lexicogramatical; em que padrões lexicais organizam o vocabulário nas estruturas morfológicas e sintáticas como sequência de unidades gramaticais e textuais.

Os processos do sistema de alinhamento morfossintático, como marcação de caso, ergatividade cindida e concordância, são analisados de acordo com os princípios tipológicos funcionais apresentados em Dixon (1979, 1994). O principal conceito na descrição de marcadores morfológicos e operações sintáticas refere-se aos primitivos sintático-semânticos (A) e (s), sujeito de verbo transitivo e intransitivo, e (P), objeto direto. Em específico, aspectos tipológicos e funcionais apresentados por Baerman et al. (2005) e Halliday e Matthiessen (2014) baseiam a terminologia descritiva e analítica dos sistemas de marcação de casos e concordância.

\subsection{Tipologia gramatical da língua matis}

A língua matis pertence ao ramo Mayoruna da família linguística Pano. Essa família contém aproximadamente 30 línguas, sendo cerca de 20 ainda faladas atualmente (a maior parte com menos de mil falantes), nas regiões da Amazônia do Brasil, Peru e Bolívia. Vários estudiosos aperfeiçoaram as propostas de parentesco da família Pano e, visto que a partir de meados do século Xx, classificações mais sistemáticas e estudos comparativos ampliaram o conhecimento das relações e mudanças históricas dessas línguas, e a estrutura interna dessa família. Dentre as línguas da família Pano, o matis tem maior proximidade de parentesco com a língua matsés, de acordo com as classificações propostas por Lanes (2005); Ribeiro (2006) e Fleck (2013).

A proposta de análise do sistema fonológico das consoantes e vogais da língua matis é apresentada no estudo de Barbosa, Netto e Matis (ms). Nesse estudo, os autores propõem que, em vez da análise da consoante tepe como variante intervocálica (Ferreira V. 2000, 2005; Ferreira R. 2001, 2005), o sistema consonantal possui o fonema tepe / $/$ / que se realiza como oclusiva alveolar, quando antecedido de silêncio e em contextos pré-nasais. Ademais, apenas em final de sílaba, o tepe [r] ocorre como variante do fonema /t/, em coda silábica, seguido de palavra iniciada por vogal. Os quadros a seguir apresentam a proposta de sistema fonológico das consoantes e das vogais em matis. 


\section{BARBOSA - Alinhamento morfossintático em Matis (Pano)}

Quadro 1. Proposta de sistema consonantal em matis (Barbosa, Netto e Matis ms)

\begin{tabular}{cccccc}
\hline Obstruinte & {$[-$ contínuo $]$} & & ts & ts & t \\
& & $p$ & t & $k$ & \\
\multirow{3}{*}{ Soante } & {$[+$ contínuo $]$} & $\beta$ & s & s & $\int$ \\
& {$[-$ nasal $]$} & w & r & j & \\
& {$[+$ nasal $]$} & $\mathrm{m}$ & $\mathrm{n}$ & & \\
\hline
\end{tabular}

Quadro 2. Proposta de sistema vocálico em matis (Barbosa, Netto e Matis ms)

\begin{tabular}{llll}
\hline+ Alta & i & i & $\mathrm{u}$ \\
- Alta & $\mathrm{e}$ & $\mathrm{a}$ & $\mathrm{o}$ \\
\hline
\end{tabular}

A ordem dos constituintes na língua matis é estruturada com base na função sintática que a oração exerce no complexo oracional. Em orações independentes, os constituintes são flexíveis, com a tendência de ocorrer na ordem sujeito-objeto-verbo, e em orações dependentes, configura-se sempre com verbo final. A respeito das unidades lexicais, palavras que compõem os sintagmas nominais possessivos ocorrem em ordem fixa, com o nome referente ao possuidor, marcado com caso genitivo, seguido do item nominal que expressa o referente possuído.

A estrutura morfológica do matis é aglutinante e sintética, com bases verbais que recebem diversos sufixos, em adição a cerca de 30 prefixos locativos referentes a partes do corpo (Barbosa ms). Não há distinção morfológica de gênero nos itens pronominais, nem de número nos itens nominais. O sistema de referência-alternada (switch-reference) envolve relação lógico-temporal e concordância de participante. O pronome de quarta pessoa estabelece a retomada interoracional de sintagma nominal introduzido no texto ou a correferência de adjunto. Diferente desse sistema, a referência análoga à função da terceira pessoa é realizada por meio dos marcadores verbais de referência-alternada.

A categoria de tempo verbal do matis é composto do não-passado em oposição ao passado. O marcador de tempo não-passado $\{-\mathrm{e}\}$ (presente ou futuro) contrasta com a categoria de tempo passado, formada por quatro graus aspectuais: passado recente $\{-a\}$ (mesmo dia); passado não-recente $\{-\beta 0\}$ (de um a três dias); passado distante $\{-\beta$ onra $\}$ (dias, meses, anos); e passado remoto experiencial \{-anpi\} (mais de 40 ou vários anos). Além dos morfemas de tempo passado, o intervalo temporal indicado pelo sufixo de passado indeterminado $\{$-nra $\}$ corresponde ao intervalo temporal dos seguintes sufixos: $\{-\beta o\},\{-\beta o n r a\}$ e $\{$-anpi\} (Ferreira R. 2005), ou seja, ao passado não-recente.

Em orações com verbo flexionado no passado, "se o locutor tiver participado do evento, o verbo é marcado por $\{-\mathrm{s}\}$ 'experimental' e, se houver apenas evidências do ocorrido, o verbo é marcado por $\{-\mathrm{k}\}$ 'inferencial'." (Ferreira R. 2005: 124). Apenas sujeitos não-participantes do discurso, como sintagmas nominais ou terceira pessoa (por meio de referência-alternada), expressam essa oposição pragmática na morfologia verbal. Em contraste, independente da participação do locutor no evento, o verbo sempre recebe o sufixo declarativo $\{-\mathrm{k}\}$ em orações com sujeitos participantes do discurso (primeira e segunda pessoas), ou orações com verbos flexionados no tempo não-passado $\{-\mathrm{e}\}$.

A gramática da língua matis reduz a valência verbal por meio do sistema de voz antipassiva; a sufixação de $\{-a n\}$ a verbos transitivos reduz a valência e torna o caso 
ergativo, na construção ativa, em caso absolutivo, na construção antipassiva. "Outra característica dessa construção é a remoção do objeto [direto].” (Ferreira R. 2005: 277), e a ocorrência em eventos no tempo presente, geralmente contínuo ou habitual, marcado com o sufixo de tempo não-passado $\{-\mathrm{e}\}$. Apesar de sintética, a gramática apresenta grande diversidade funcional de sufixos verbais, com várias construções, por exemplo, direcionais, negativas, causativas. Demais aspectos a respeito do alinhamento morfológico e do sincretismo de casos são analisados nas seguintes seções.

\section{Morfologia}

Na presente descrição do alinhamento morfossintático em matis, as notações (A), (S) e (P) são utilizadas, com base no conceito de primitivos sintáticos-semânticos dos argumentos oracionais que operam no nível subjacente da gramática (Dixon 1979, 1994). Essas noções básicas estabelecem a terminologia analítica na descrição morfológica apresentada nesta seção. Com base nesses princípios, é apresentada a análise dos sistemas de alinhamento morfológico que identificam as funções sintáticas dos argumentos na oração. Em seguida, as relações lexicogramaticais dos argumentos e adjuntos que formam o sincretismo de casos na língua matis são analisadas.

\subsection{Ergatividade morfológica}

O sistema nominal de alinhamento morfológico na língua matis segue o padrão ergativo-absolutivo. ${ }^{3}$ Nesse sistema, sintagmas nominais em função de (A) são marcados com morfema nasal, e em função de (S) ou (P), com morfema zero. Em contraste com os argumentos nominais, o sistema pronominal é caracterizado pela cisão na categoria de número, pois o padrão ergativo-absolutivo é seguido somente pelos pronomes do singular. Essa cisão na ergatividade é caracterizada pela categoria de plural da primeira pessoa, cuja forma nuki compreende quaisquer das relações gramaticais (alinhamento direto), e plural das segunda e quarta pessoas (alinhamento nominativo-acusativo).

Quadro 3. Alinhamento nominal e pronominal em matis

\begin{tabular}{cccc}
\hline & $\mathrm{A}$ & $\mathrm{S}$ & $\mathrm{P}$ \\
\hline NOME & $\mathrm{n}$ & $\varnothing$ & $\varnothing$ \\
$1 \mathrm{SG}$ & $\mathbf{i n} \boldsymbol{\beta} \mathrm{i}$ & $\mathbf{i} \boldsymbol{\beta} \mathbf{i}$ & $\mathbf{i} \boldsymbol{\beta} \mathbf{i}$ \\
$2 \mathrm{SG}$ & $\min \boldsymbol{\beta i}$ & $\mathbf{m i} \boldsymbol{\beta} \mathbf{i}$ & $\mathbf{m i} \boldsymbol{\beta i}$ \\
$4 \mathrm{SG}$ & an $\beta \mathrm{i}$ & $\mathbf{a} \boldsymbol{\beta} \mathbf{i}$ & $\mathbf{a} \boldsymbol{\beta} \mathbf{i}$ \\
$1 \mathrm{PL}$ & nuki & nuki & nuki \\
$2 \mathrm{PL}$ & mikwi & mikwi & mitso \\
$4 \mathrm{PL}$ & akwi & akwi & ato \\
\hline
\end{tabular}

${ }^{3} \mathrm{O}$ alinhamento ergativo-absolutivo é descrito na maior parte das línguas da família Pano (com alguma cisão, geralmente nas categorias pronominais), como, por exemplo, Kaxinawa (Camargo 2005), Marubo (Costa e Raquel 1998), Matsés (Fleck 2005, 2010), Shipibo-Konibo (Valenzuela 2010). 


\section{BARBOSA - Alinhamento morfossintático em Matis (Pano)}

O morfema de caso ergativo em matis é realizado na forma da consoante nasal [n], anexada à direita de nomes terminados em vogais orais, o que resulta na nasalização fonética dessas vogais. Na anexação de nomes terminados em coda silábica consonantal, esse morfema realiza-se na forma da consoante nasal antecedida da vogal alta central [in]. Considerando que no léxico da língua matis, palavras com sílabas finais abertas são menos marcadas, o morfema de caso ergativo é representado com o fonema nasal $/ \mathrm{n} /$. Como apresentado nas seguintes orações, esse morfema de caso ergativo opera no nível do sintagma nominal e se anexa ao item lexical mais à direita do sintagma, o que o caracteriza como ênclise $\{=\mathrm{n}\} .^{4}$
(1) wapa
awin $=\mathrm{n}$
tumi-Ø
pe-a-s
cachorro fêmea-ERG
tumi-ABS
morder-PST.REC-3EXP
'A cadela mordeu o Tumi.'
(2) tumi-Ø us-a-s
tumi-ABS dormir-PST.REC-3EXP
'O Tumi dormiu.'

Nessas orações, o sintagma nominal tumi, argumento (P) do verbo transitivo pe 'morder' e argumento (s) do verbo intransitivo $u s$ 'dormir', recebe o morfema zero $\{-\varnothing\}$ de caso absolutivo. Em contrapartida, o sintagma nominal wapa awin 'cadela', argumento (A), recebe a ênclise nasal $\{=\mathrm{n}\}$, o que configura o padrão de alinhamento ergativoabsolutivo. Assim como sintagmas nominais, os argumentos pronominais do singular também seguem esse padrão de alinhamento, conforme ilustram as seguintes orações que contêm o pronome de segunda pessoa do singular, ergativo-absolutivo (A/SP).

$\begin{array}{lllll}\text { (3) } \min \boldsymbol{\beta i} & \text { nukun } & \text { tiktun } & \text { kekik-rapa } & \text { ak-a-k } \\ \text { 2SG.ERG } & \text { 1POSS.SG } & \text { tiktun } & \text { kekik-ENF } & \text { matar-PST.REC-DECL }\end{array}$

'(O filho disse:) "Por que você matou meu tëktun kekik?".'
(4) ara
nes-a-k
Bira
mißi
kapa
e.aí banhar-PST.REC-DECL
já 2sG.ABS
perguntar

'(O irmão) perguntou (pra namorada): “e aí, você já banhou?’.'
(5) mitsi mi $\beta \mathbf{i} \quad$ го $\beta \mathrm{o}=\mathrm{n} \quad$ tintema
onde 2SG.ABS humano=ERG acertar

'(E a onça perguntou:) “Onde o humano acerta você?”.'

${ }^{4}$ As glosas são apresentadas conforme as seguintes abreviações (baseadas na lista de Leipzig): 1 primeira pessoa, 2 segunda pessoa, 3 terceira pessoa, 4 quarta pessoa, A sujeito de verbo transitivo canônico, ABS absolutivo, ACC acusativo, AGR concordância, ANT anterior, DECL declarativo, ENF enfático, ERG ergativo, EXP experiencial, GEN genitivo, HAB habitual, ID idêntico, IMP imperativo, INs instrumental, LOC locativo, NID nãoidêntico, NOM nominativo, NPST não-passado, NREC não-recente, P objeto direto de verbo transitivo canônico, PL plural, POSS possessivo, PRS presente, PST passado, REC recente, RECP recíproco, RED reduplicante, s sujeito de verbo intransitivo canônico, SG singular, SIM simultâneo, TOT totalidade, oração marcada > oração de referência. 
A estrutura etimológica dos itens pronominais absolutivos (i $\beta i$, mi $\beta i$ e $a \beta i)$ são constituídas do processo de lexicalização da raiz pronominal com a forma / $\beta \mathrm{i} /$ na sílaba final (Ferreira R. 2005). Nos pronomes ergativos, a consoante nasal seguida de / $\beta i /$ sugere que a lexicalização pronominal tem contribuído na gramaticalização da ergatividade na língua matis, o que indica, nos termos de Halliday e Matthiessen (2014), a estreita relação de categorias funcionais no nível lexicogramatical.

Em adição aos pronomes referentes aos participantes do discurso (primeira e segunda pessoas), o léxico do matis contém itens pronominais de quarta pessoa, que retomam referências contextuais de sintagmas nominais ou implementam relações correferenciais entre adjuntos e sintagmas nominais. ${ }^{5}$ As orações apresentadas a seguir são constituídas dos pronomes de quarta pessoa do singular $a n \beta i$ e $a \beta i$, que operam no sistema de alinhamento morfossintático ergativo-absolutivo (A/sP).

(6) $\mathbf{a n} \beta \mathbf{i}$

isek $=$ nu

matses-rene-k

4ERG

ver $=$ NID.SIM.P $>\mathrm{A} / \mathrm{s}$

tornar.humano-PST.HAB-DECL

'Dizem que ele (a) vê quando (ela) sempre se torna humana.'

(7) niktope $=$ kin

aßi $\quad$ pimos $\sim$ pi-mos

levantar $=$ ID.SIM. $\mathrm{A} / \mathrm{s}>\mathrm{A} \quad 4 \mathrm{ABS} \quad$ TOT $\sim$ braço-morder

'E quando (a onça se) levantou, (ela) o mordeu em ambas as patas [...]'

(8) pe-as

aßi usi-a-s

dormir-ID.ANT.A/s $>$ S 4 ABS

'Depois que comeu, ele dormiu.'

Os itens pronominais de quarta pessoa do singular seguem o padrão ergativoabsolutivo, com a forma $a \beta i$ em função de (P) e (S), e $a n \beta i$, em função de (A). Em contraste com as unidades pronominais do singular, que seguem o padrão ergativo-absolutivo, as formas pronominais do plural seguem padrões distintos de alinhamento morfossintático. Os pronomes de segunda e quarta pessoas do plural, por exemplo, seguem o alinhamento morfossintático nominativo-acusativo.

Os pronomes de quarta pessoa do plural (nominativo-acusativo) são constituídos da forma ato em função de argumento (P), e akwi em função de (A) e (s). Sobre os pronomes de segunda pessoa do plural, esse padrão de alinhamento é apresentado nas seguintes orações constituídas do pronome de segunda pessoa do plural: o pronome $m i$, em função de (A) e (S), recebe o marcador de caso nominativo \{-kwi\}; e, em função de (P), é anexado com o sufixo de caso acusativo $\{$-tso $\}$ (AS/P).

(9) mi-kwi

2PL-NOM

queixada

'Vocês mataram a queixada.' sek-a-k

furar-PST.REC-DECL

${ }^{5}$ As demais formas pronominais de quarta pessoa do plural e suas funções gramaticais, apresentadas no quadro 3, foram identificadas em trabalho de campo por meio da aplicação de testes de elicitação. 


\section{BARBOSA - Alinhamento morfossintático em Matis (PAno)}

(10) mi-kwi us-a-k

2PL-NOM dormir-PST.REC-DECL

'Vocês dormiram.'

$\begin{array}{lll}\text { (11) in } \beta \mathrm{i} & \text { mi-tso } & \text { ret-a-k } \\ \text { 1sG.ERG } & \text { 2PL-ACC } & \text { cortar-PST.REC-DECL } \\ \text { 'Eu cortei vocês.' } & \end{array}$

Essa cisão no alinhamento ergativo-absolutivo é restrita aos pronomes da categoria de número plural, o que inclui as formas de segunda e quarta pessoas, que seguem o padrão nominativo-acusativo; assim como a forma referente a primeira pessoa do plural, que segue o padrão direto. As orações a seguir, por exemplo, contêm o pronome de primeira pessoa do plural, cuja única forma pronominal nuki implementa as relações gramaticais de argumentos (A), (S) e (P); representação direta da marcação de caso de alinhamento morfossintático (ASP).

(12) nuki raßitsik atsa pe-a-k

1PL.A pouco mandioca comer-PST.REC-DECL

'Nós comemos poucas mandiocas.'

(13) nuki tşat $\beta$ ut uš-a-k

1PL.S tarde dormir-PST.REC-DECL

'Nós dormimos tarde.'

$\begin{array}{rlll}\text { (14) kamun-n } & \text { nuki } & \text { is }=\text { as } & \text { abat-a-s } \\ \text { onça-ERG } & \text { 1PL.P } & \text { ver=ID.ANT.A/s }>\text { S } & \text { correr-PST.REC-3EXP }\end{array}$

'A onça nos viu e correu.'

Diferente dos padrões de alinhamento ergativo-absolutivo e nominativo-acusativo, a forma pronominal referente a primeira pessoa do plural opera no sistema de alinhamento direto, pois não há marcação fonológica ou morfológica das relações gramaticais. Em orações constituídas de argumentos na forma de pronomes de primeira pessoa plural, as relações gramaticais e semânticas são implementadas por meio do contexto discursivo ou mediante a ordem dos constituintes na oração.

Com base nos dados já descritos, a ergatividade cindida é condicionada não pela propriedade semântica ou lexical do verbo, mas pela propriedade lexical do argumento pronominal. Em geral, a classe nominal e pronominal do singular de primeira, segunda e quarta pessoas seguem o sistema de alinhamento ergativo-absolutivo. $\mathrm{O}$ alinhamento morfológico em matis é, portanto, caracterizado pelo sistema de ergatividade, pois essas unidades também seguem esse padrão em orações constituídas de verbos ativos ou estativos, ou flexionados nas demais categorias de tempo, aspecto e modo.

\subsection{Sincretismo de casos}

A respeito de categorias nominais da língua matis, o clítico que indica o caso ergativo também indica os casos genitivo e instrumental, o que configura o sistema de sincretismo de 
casos. Esse sistema é definido como a combinação de diferentes categorias funcionais, em contextos gramaticais específicos, indicadas por uma mesma forma linguística (Baerman et al. 2005). Assim como descrito em diversas línguas da família Pano (Barbosa 2018), o sincretismo de casos em matis é formado com a anexação da consoante nasal coronal. $\mathrm{O}$ caso genitivo é apresentado na oração a seguir.

(15) ak-a-k

kanek akit tiktun kekik=n

ßakui- $\varnothing$

matar-PST.REC-DECL

dizer aquele

tiktun kekik $=$ GEN

filho-ABS

'Dizem que mataram aquele filhote de Tiktun Kekik (tipo de sapo).'

Nessa construção possessiva em função de objeto direto, o caso genitivo é anexado ao termo possuidor Tìktun Kekik, que é seguido do termo possuído $\beta a k u i$ 'filhote'. Além da anexação em sintagmas nominais, o caso genitivo também ocorre nos pronomes possessivos do singular nukun 'primeira pessoa', min 'segunda pessoa' e awin 'quarta pessoa'; e nas formas correspondentes do plural nukin, mitson e aton. O caso genitivo, em específico, relaciona-se a referentes animados, mas o caso instrumental, exemplificado na oração a seguir, somente a referentes inanimados.

(16) tșira $\beta o-\beta o$ mulher-PL

raßikpa awin duas 4Poss

ßipin $=\mathbf{n}$

seiva $=$ INS akat akat-pa

RED ferir-ENF
ikek
ßirike-pe-so
istit-e-k
e
em.pé-estar-NID.SIM.A/S $>$ P encontrar-NPST-DECL
'(Ele) encontrou duas mulheres', que estavam em pé e pintadas com suas seivas.'

Apesar da marcação morfológica dos casos genitivo e instrumental com a anexação da ênclise na formal da consoante nasal coronal, o caso genitivo é marcado em sintagmas nominais ou itens pronominais com referentes animados e o caso instrumental, apenas em sintagmas nominais com referentes inanimados. Esses aspectos do caso instrumental são equivalentes aos aspectos do caso locativo, que designa o espaço ou direção em que se realiza a ação verbal. Com isso, as funções do caso locativo no sincretismo de casos são representadas na análise do caso instrumental.

A forma da consoante coronal nasal, em todas as funções do sincretismo de casos, apresenta a mesma variação consonantal quando antecedida de consoante, e assim é representada como ênclise $\{=n\}$. A relação das funções casuais com o traço de animacidade do referente é identificada na terminação nasal dos sintagmas nominais. No seguinte quadro, apresento a relação lexicogramatical das categorias morfossintáticas do sincretismo de casos com a função semântica de animacidade dos referentes nominais. 


\section{BARBOSA - Alinhamento morfossintático em Matis (PAno)}

Quadro 4. Sistema lexicogramatical do sincretismo de casos em matis ${ }^{6}$

\begin{tabular}{ccc}
\hline & 'menino' (animado) & 'grelha' (inanimado) \\
\hline GEN & papin & tapu \\
ERG & papin & tapun \\
INS & papi & tapun \\
\hline
\end{tabular}

No nível lexicogramatical do sincretismo, as unidades lexicais com referentes animados recebem o marcador de caso genitivo, que relaciona dois sintagmas nominais em função de possuidor e possuído. A respeito das unidades lexicais com referentes inanimados, elas recebem o marcador de caso instrumental, que indica o objeto/instrumento com o qual a ação é realizada. No exemplo a seguir, constituído de oração com predicado na função de verbo intransitivo, esses casos compõem a configuração morfológica da construção possessiva instrumental.

$\begin{array}{llll}\begin{array}{l}\text { (17) } \text { papi }=\mathbf{n} \\ \text { menino }=\mathbf{G E N}\end{array} & \begin{array}{l}\text { tapu }=\mathbf{n} \\ \text { grelha }=\mathbf{I N S}\end{array} & \text { nami- } \varnothing & \text { t } \\ \text { carne-ABSo-a-s } & \text { assar-PST.REC-3EXP }\end{array}$

'A carne assou com a grelha do menino.'

Referentes inanimados usados como meio para realizar determinada ação são geralmente associados ao espaço em que se passa essa ação, a exemplo do referente do sintagma nominal tapu 'grelha', instrumento e local onde a ação de assar a carne é realizada. Não obstante a ambiguidade funcional dos casos locativo e instrumental, a identificação do marcador de caso genitivo é, diferente de referentes inanimados, estabelecida a partir da categoria semântica de referentes animados.

Apesar da distinção de animacidade entre os casos genitivo e instrumental, o morfema de caso ergativo é anexado tanto a unidades lexicais que expressam referentes animados, dotados de volição, como inanimados, desprovidos de volição. Nesse sentido, o mesmo morfema nasal $\{=\mathrm{n}\}$, anexado a sintagmas nominais que compõem construções possessivas em início de oração com verbo ergativo, admite mais de uma leitura funcional.

(18) papi $=\mathbf{n}$

menino $=\mathbf{E R G}$

'O menino assou a carne com a grelha.'

(19) $\mathrm{papi}=\mathbf{n}$

menino $=\mathbf{G E N}$

'A grelha do menino assou a carne.' tapu $=\mathbf{n} \quad$ nami- $\varnothing \quad$ tfamo-a-s

grelha $=$ INS carne-ABS

nami-Ø

carne-ABS t $\int a m o-a-s$ assar-PST.REC-3EXP

Determinados contextos com verbo ergativo que estabelecem a correspondência do argumento (s), nami 'carne' em 17, com o argumento (P), nos exemplos 18 e 19, tem como resultado a ambiguidade funcional do sincretismo de casos. Na oração intransitiva

${ }^{6}$ Os pronomes demonstrativos, analisados em Barbosa (2018) como variantes lexicais do sincretismo, comportam-se de maneira similar aos sintagmas nominais, recebendo sufixo de plural $\{-\beta o\}$, por exemplo. Sendo assim, neste trabalho, essa categoria pronominal é considerada na própria análise do sintagma nominal, pois ambos concluem as mesmas proposições na proposta de descrição aqui apresentada. 
apresentada em 17, a função genitiva do sintagma nominal com referente animado, papi 'menino', é equivalente à função ergativa da oração transitiva, em 18 (GEN=ERG). Em contrapartida, a função instrumental do sintagma nominal inanimado, tapu 'grelha', é equivalente à função ergativa, no exemplo 19 (INS = ERG).

No entanto, se esse sintagma com referente inanimado, tapu 'grelha' é antecedido do argumento (P) nami 'carne', anula-se a ambiguidade funcional dos marcadores genitivo e instrumental com o marcador de caso ergativo. O exemplo a seguir apresenta essa estrutura oracional com o argumento absolutivo seguindo imediatamente o argumento ergativo.

\begin{tabular}{|c|c|c|c|}
\hline $\begin{array}{l}\text { (20) } \mathrm{papi}=\mathbf{n} \\
\text { menino }=\mathbf{E R G}\end{array}$ & $\begin{array}{l}\text { nami- } \varnothing \\
\text { carne-ABS }\end{array}$ & $\begin{array}{l}\text { tapu }=\mathbf{n} \\
\text { grelha }=\mathbf{I N S}\end{array}$ & $\begin{array}{l}\text { t } \int a m o-a-S \\
\text { assar-PST.REC-3EXP }\end{array}$ \\
\hline
\end{tabular}

Nessa configuração morfossintática, a função ergativa é atribuída somente ao sintagma nominal de referente animado, em função de argumento (A), visto que esse sintagma é seguido do argumento absolutivo (P). Ou seja, os diferentes sentidos da mesma estrutura dependem do contexto sintático de construções possessivas; possuidor seguido imediatamente do possuído. Assim sendo, a condição necessária para a associação funcional do caso ergativo com os casos genitivo ou instrumental é a formação de orações constituídas de construção possessiva em função de sujeito de verbo ergativo.

Aspectos gramaticais e funcionais dos casos do sincretismo indicam que a ergatividade morfológica é resultado da reanálise de construções possessivas e instrumentais, por meio de processos de lexicalização e gramaticalização (Barbosa 2018). Nas construções possessivas instrumentais em função de argumento (A), o caso genitivo, marcado no possuidor, ou caso instrumental, marcado no possuído, é reanalisado como caso ergativo. Portanto, com a gramaticalização da ergatividade em sintagmas nominais e em formas pronominais do singular, processos de lexicalização afetaram o sistema de pronomes pessoais, tendo como resultado a cisão na ergatividade.

\section{Sintaxe}

Os sistemas gramaticais de alinhamento sintático e concordância de participante na língua matis são descritos na presente seção, conforme a noção de pivô sintático (Dixon 1979, 1994). Nas subseções a seguir, apresento a descrição do alinhamento sintático e, em seguida, a análise da relação funcional entre a categoria de caso e a concordância de participante na língua matis.

\subsection{Ergatividade sintática}

No nível da oração simples, o sistema básico de alinhamento morfológico da língua matis caracteriza-se como ergativo-absolutivo. No nível sintático do complexo oracional, o alinhamento também é caracterizado pelo padrão ergativo-absolutivo. Assim, na coordenação de duas orações, o sistema de alinhamento sintático do matis estabelece a correferência de argumentos que operam em função de argumentos (s) e (P). Desse modo, 


\section{BARBOSA - Alinhamento morfossintático em Matis (PAno)}

no complexo oracional constituído de argumentos absolutivos com referentes em comum, o argumento da segunda oração é geralmente omitido.

(21) tumi-Ø

tso-a-s

tupa $=\mathrm{n}$

tumi-ABS retornar-PST.REC-3EXP

'O Tumi retornou e a Tupa (o) viu.'

tupa $=$ ERG

is-a-s

ver-PST.REC-3EXP

Nesse exemplo, o caso absolutivo equivale aos argumentos (s) e (P), em oposição ao caso ergativo da segunda oração. Assim, o caso absolutivo é o pivô sintático de orações coordenadas, pois o referente do sintagma nominal do argumento s é idêntico àquele em função de argumento O. Por outro lado, conforme apresentado no exemplo a seguir, nas relações interoracionais em matis, a condição sintática necessária para que os argumentos em função de argumento (s) e (A) tenham referentes idênticos é a anexação de morfemas verbais de correferência.
(22) tumi-Ø
tşo $=$ sun
tupa- $\varnothing$
is-a-s
tumi-ABS
retornar $=$ ID.ANT.A $/ \mathrm{s}>\mathrm{A}$
'O Tumi retornou e (ele) viu a Tupa.'
tupa-ABS
ver-PST.REC-3EXP

A primeira oração desse exemplo é composta do sintagma nominal tumi e o verbo intransitivo tso 'retornar'. Nessa oração, o verbo é flexionado com o marcador de correferência $\{=$ Sun $\}$ do sistema de referência-alternada. Na oração seguinte, que contém o sintagma verbal composto do verbo transitivo finito isas 'viu', o sujeito correferente tumi é omitido, pois o referente é idêntico ao sintagma nominal da oração anterior. Portanto, conforme a necessidade ou intenção discursiva do locutor, o sistema de referênciaalternada é o mecanismo que a língua matis com padrão ergativo possui para implementar o padrão acusativo, com continuidade entre (S) e (A).

\subsection{Caso e concordância}

Os processos de concordância na língua matis são marcados na morfologia de adjuntos adverbiais, desencadeados pela categoria da função sintática dos participantes da oração aos quais os adjuntos se referem (Ferreira R. 2017). ${ }^{7}$ Os sufixos que concordam com os argumentos (A), (S) ou (P) se anexam a itens adverbiais - também denominados predicativos secundários (Schultze-Berndt e Hilmmelmann 2004), que indicam alguma circunstância temporal, local etc. do evento expresso pelo verbo. As seguintes orações ilustram o sistema de concordância no domínio intraoracional em matis, com adjuntos que expressam informações de tempo, modo e local.

(23) isek-e-k

ver-NPST-DECL

'(Ela) sempre olha (para a cuia).'

${ }^{7}$ O sistema de concordância (de participante) nas línguas da família Pano é analisado, por exemplo, na língua shipibo-konibo (Camacho 2010; Valenzuela 2003, 2005). 
(24) paren-ek amak=ek kapun-e-k

assim-AGR.S pisar=ID.SIM.A/s $>\mathrm{S}$ andar-NPST-DECL

'Dizem que (o tamanduá) anda pisando dessa maneira.'

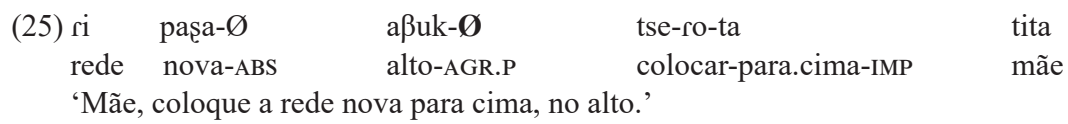

Como apresentado nesses exemplos, a concordância com o argumento (A) é indicada no morfema $\{-\operatorname{kin}\}$; com o argumento (s), no morfema $\{$-ek\}; e com o argumento (P), sem forma fonológica, é indicada com o morfema zero $\{-\varnothing\}$. Os marcadores adverbiais específicos para cada função argumental no domínio intraoracional compõem o sistema de concordância de participante no padrão de alinhamento tripartido. As formas anexadas a adjuntos, por exemplo, com informação temporal de evento 'não-passado' correspondem aos marcadores $\{$-kin $\},\{$-ek $\}$ e $\{-\varnothing\}$, e de evento 'passado', aos marcadores $\{$-sun $\},\{$-as $\}$ e $\{-\varnothing\}$ (Ferreira R. 2017).

A concordância de participante também se realiza no sistema de referência-alternada da língua matis, com clíticos verbais que expressam a função sintática de argumentos entre orações. A anexação desses clíticos indica a correferência de argumentos da oração marcada com os argumentos da oração de referência ou matriz (geralmente a oração seguinte, conforme apresentado nos exemplos desta subseção). A correferência argumental ocorre como processo sintático do sistema de concordância de participante, em que a categoria de caso do participante da oração de referência é indicada por meio da forma morfológica da ênclise anexada ao verbo da oração marcada.

Quadro 5. Marcadores de concordância de participante em matis

\begin{tabular}{cccc}
\hline & Simultâneo & $\begin{array}{c}\text { Sequencial } \\
\text { [anterior] }\end{array}$ & $\begin{array}{c}\text { Sequencial } \\
\text { [causal] }\end{array}$ \\
\hline $\mathrm{A} / \mathrm{S}>\mathrm{A}$ & kin & sun & nun \\
$\mathrm{A} / \mathrm{S}>\mathrm{S}$ & ek & aș & nuș \\
$\mathrm{A} / \mathrm{S}>\mathrm{P}$ & so & akșo & ekșo \\
\hline
\end{tabular}

Essas ênclises verbais, do sistema de referência alternada em matis (cf. Barbosa ms; Ferreira R. 2005, 2017), indicam a manutenção de argumentos entre orações, ${ }^{8}$ as relações lógico-temporais e a concordância de participante. Na concordância, os marcadores implementam a correferência do argumento, da oração marcada, em relação à função sintática do argumento da oração de referência. Esses clíticos, anexados aos sintagmas verbais de orações dependentes, relacionam participantes no domínio interoracional, sempre com verbos em posição final. As orações a seguir apresentam o sistema de concordância de participante, com os marcadores de argumentos da oração de referência no padrão de alinhamento tripartido (A/s/P).

${ }^{8} \mathrm{~A}$ indicação de alternância de sujeito entre orações no sistema de referência-alternada da língua matis é realizada com os clíticos $\{=\mathrm{nu}\},\{=\mathrm{an}\},\{=\mathrm{en}\}$ e $\{=\mathrm{ak}\}$ (cf. Barbosa ms). 


\section{BARBOSA - Alinhamento MORFossintático em Matis (PANo)}

(26) kuan=kin

ir $=$ ID.SIM.A $/ \mathrm{s}>\mathrm{A}$

ßakun

mel nißine- $\beta$ uan-e-k

procurar-levar-NPST-DECL

'Enquanto (o tamanduái) estava indo, (elej) procurava por mel.'

(27) kamun-rapa=n

onça-ENF=ERG

sai

istit $=\mathbf{e k}$

kuan-a-k

'Enquanto a onça estava indo, (ela $)$ encontrou o tamanduá.'

(28) $\mathrm{pe}=\mathbf{s} \mathbf{0}$

ano-ßentsik

tşotka-kapa-a-k

fazer=NID.SIM.A $/ \mathrm{S}>\mathrm{P} \quad$ lá-rápido

furar-para.baixo-PST.REC-DECL

'Enquanto (a onça $\mathrm{a}^{\mathrm{j}}$ ) fazia isso lá rápido, (o tamanduá $\mathrm{a}^{\mathrm{j}}$ ) furou de cima para baixo.'

Nessas orações com eventos simultâneos, a concordância do sujeito da oração marcada com o argumento (A) da oração de referência é indicada no marcador $\{=$ kin $\}$; com o argumento (s), no marcador $\{=\mathrm{ek}\}$; ou com o argumento (P), no marcador $\{=\mathrm{So}\}$. No sistema de referência-alternada da língua matis, a categoria funcional dos marcadores de eventos simultâneos se opõe à categoria dos marcadores de eventos sequenciais, com ou sem relação causal. As orações a seguir apresentam os clíticos de concordância em eventos sequenciais, sem relação causal.

(29) tşuma

kuis=sun $\quad$ sußu

tsinan-a-k

cuia

tirar $=$ ID.ANT.A $/ \mathrm{s}>\mathrm{A}$ casa

deixar.no.canto-PST.REC-DECL

'Dizem que depois que (eles) tiraram a cuia, deixaram-na no canto da maloca.'

(30) moa-nan

tşuiek $=\mathbf{a s s}$

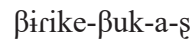

mentir-RECP contar $=$ ID.ANT.A $/ \mathrm{s}>\mathrm{S}$

sentar.PL-para.baixo-PST.REC-3EXP

'Depois que (eles) mentiram um para o outro, sentaram-se.'

(31) in $\beta$ i

miste

piş=akșo

tumi $=\mathrm{n}$

1SG.ERG lenha cortar $=$ NID.ANT.A $/ \mathrm{s}>\mathrm{P} \quad$ tumi $=$ ERG

'Depois que eu cortei a lenha, o Tumi me abraçou.'

Em ambos os domínios gramaticais (intraoracional e interoracional), as relações correferenciais das funções sintáticas no sistema de concordância de participante seguem o padrão de alinhamento tripartido (A/S/P). Nesses sistemas tripartidos, o argumento (A) é indicado com a consoante nasal /n/; o argumento ( $\mathrm{S}$ ), com a consoante obstruinte $/ \mathrm{s} /$ (ou $/ \mathrm{k} /$ em evento sequencial); e - no domínio interoracional, o argumento (P), com a obstruinte /s/ seguida da vogal posterior menos alta /o/.

As relações entre alinhamento e concordância caracterizam a morfossintaxe verbal do matis. Enquanto a ergatividade sintática alinha os argumentos (S) e (P), os marcadores de concordância de participante permitem que os argumentos (S) e (A) sejam alinhados. No entanto, tendo em vista que os argumentos (S) e (P) se identificam no alinhamento sintático, construções de concordância com argumento (P) também apresentam outras funções sintáticas e pragmáticas; a serem descritas. 


\section{Conclusão}

Os processos gramaticais do alinhamento morfossintático na língua matis envolvem categorias nominais e pronominais, e se estendem a categorias verbais e adverbiais. As categorias nominais e pronominais são caracterizadas com processos morfológicos de marcação de caso e a relação funcional com o sincretismo de casos. As categorias verbais e adverbiais relacionam os processos sintáticos de correferenciação de argumentos oracionais e a concordância de participantes com as funções gramaticais de argumentos, em domínio interoracional e intraoracional.

O alinhamento morfológico segue o padrão ergativo-absolutivo, caracterizado pela ergatividade cindida no contexto restrito aos pronomes do plural. O morfema nasal de caso ergativo também indica as funções de casos genitivo e instrumental, o que configura o sincretismo de casos. Esse sincretismo em matis (e outras línguas da família Pano) é resultado de processos de lexicalização e gramaticalização, por meio da reanálise dos casos, no contexto de construções possessivas instrumentais.

A marcação de caso genitivo é restrita ao traço animado e de caso instrumental, ao traço inanimado, enquanto o caso ergativo ocorre com ambos os traços. Nesse sentido, enquanto o caso ergativo relaciona-se à categoria de tempo, os demais casos, à animacidade (genitivo animado e instrumental inanimado). Esses aspectos caracterizam a oposição de animacidade no sistema de marcação de caso; referentes animados, caso genitivo; referentes humanos, caso ergativo; e referentes inanimados, caso instrumental. ${ }^{9}$

Orações complexas seguem o padrão ergativo-absolutivo, o que estabelece a correferência de argumentos em função de sujeito e objeto direto, com base no pivô absolutivo. A identificação de argumentos em função de sujeito em ambas as orações é estabelecida com o processo de anexação verbal dos marcadores de concordância de participante. Esses marcadores verbais de concordância interoracional também ocorrem em adjuntos adverbiais em domínio intraoracional, o que indica a interrelação funcional desses sistemas que seguem o padrão de alinhamento morfossintático tripartido.

Cadeias referenciais de longa distância requerem sistemas que especificam as funções sintáticas desempenhadas pelos argumentos verbais, conforme a concordância de participante no padrão de alinhamento tripartido. Em contraste, relações gramaticais no domínio da oração identificam mais de uma função sintática com somente uma forma lexical, como o alinhamento morfológico ergativo-absolutivo. A função sintática de argumentos da oração, portanto, implementa processos de concordância inerente no domínio da oração, e de concordância contextual, no domínio interoracional.

\section{Referências}

Arisi, Bárbara M. (2007). Matis e Korubo - contato e índios isolados no Vale do Javari, Amazônia (Dissertação mestrado em Linguística). Universidade Federal de Santa Catarina.

${ }_{9}^{9} \mathrm{O}$ caso comitativo em matis, geralmente marcado em algumas línguas europeias, por exemplo, com a mesma forma que o caso instrumental ('com' e 'with', por exemplo), é indicado com os seguintes sufixos, cuja forma varia conforme a função sintática do argumento na oração: (A) $\{-\beta \dot{i t a n}\}$, (S) $\{-\beta$ it $\}$ e (P) $\{-\beta$ ita $\}$ (Ferreira R. 2005). 


\section{BARBOSA - Alinhamento morfossintático em Matis (Pano)}

Arisi, Bárbara M. (2011). A dádiva, a sovinice e a beleza. Economia da Cultura Matis, Vale do Javari, Amazônia (Tese doutorado em Linguística).Universidade Federal de Santa Catarina.

Arisi, Bárbara M. (2012). La no-frontera Pano: Etnónimos como categorías alternativas y múltiples entre Matis y Korubo. Tipiti 10(1): 19-36. https://digitalcommons.trinity.edu/tipiti/vol10/iss1/2

Arisi, Bárbara M. (2017). Isolados e ilhados: indigenismo e conflitos no Vale do Javari, Amazônia. Estudos Ibero-Americanos 43(1): 49-66. https://doi.org/10.15448/1980-864X.2017.1.24482

Baerman, Matthew; Brown, Dunstan; Corbett, Greville G. (2005). The syntax-morphology interface: A study of syncretism. Cambridge: Cambridge University Press.

Barbosa, Raphael A. O. (2018). Gramaticalização do sincretismo de casos em línguas da família Pano. LINCOM Studies in Language Typology (LSTL) 31.

Barbosa, Raphael A. O. (ms). Switch-reference in Matis (Panoan).

Barbosa, Raphael A. O.; Netto, Waldemar F.; Matis, Bushe (ms). Sistema fonológico da língua matis (Pano).

Bowern, Claire (2008). Linguistic fieldwork: A practical guide. Basingstoke: Palgrave Macmillan.

Chelliah, Shobhana; Reuse, Willem de (2011). Handbook of descriptive linguistic fieldwork. Springer.

Crowley, Terry (2007). Field linguistics: A beginner's guide. Oxford: Oxford University Press.

Dixon, R. M. W. (1979). Ergativity. Language 55(1): 59-138. https://www.jstor.org/stable/412519

Dixon, R. M. W. (1994). Ergativity. Cambridge: Cambridge University Press.

Ferreira, Rogério V. (2001). Língua Matis: Aspectos descritivos da morfossintaxe (Dissertação mestrado em Linguística). Universidade Estadual de Campinas. http://repositorio.unicamp.br/jspui/handle/REPOSIP/268999

Ferreira, Rogério V. (2005). Língua Matis (Pano): Uma descrição gramatical (Tese doutorado em Linguística). Universidade Estadual de Campinas. http://repositorio.unicamp.br/jspui/handle/REPOSIP/270244

Ferreira, Rogério V. (2012). Aspectos tipológicos do 'switch-reference' em línguas da família Pano. In Edson Rosa de Souza (org.), Funcionalismo Linguístico: Análise e descrição, pp. 197-223. São Paulo: Contexto.

Ferreira, Rogério V. (2017). Concordância de participante em matis (Pano). In Pilar Valenzuela; Antoine Guillaume (eds.), Estudios sincrónicos y diacrónicos sobre lenguas Pano y Takana. Amerindia 39(2): 379-406.

Ferreira, Vitória R. S. (2000). Língua Matis (Pano): Uma análise fonológica (Dissertação mestrado em Linguística). Universidade Estadual de Campinas. http://repositorio.unicamp.br/jspui/handle/REPOSIP/268998

Ferreira, Vitória R. S. (2005). Estudo lexical da língua Matis: Subsídios para um dicionário bilíngue (Tese doutorado em Linguística). Universidade Estadual de Campinas.

http://repositorio.unicamp.br/jspui/handle/REPOSIP/270233 
Fleck, David W. (2013). Panoan language and linguistics. Anthropological papers of the American Museum of Natural History 99. New York. http://digitallibrary.amnh.org/bitstream/handle/2246/6448/AP99.pdf?sequence=1

Halliday, Michael \& Matthiessen, Christian (2014). An introduction to functional grammar [4rd edn]. London: Arnold.

Instituto Socioambiental (2014). Povos indigenas no Brasil. https://pib.socioambiental.org/pt/povo/matis

Lanes, Elder J. (2005). Aspectos da mudança lingüistica em um conjunto de línguas Amazônicas: As línguas Pano (Tese doutorado em Linguística). Universidade Federal do Rio de Janeiro.

Ribeiro, Lincoln A. A. (2006). Uma proposta de classificação interna das línguas da família Pano. Revista Investigações. Lingüistica e Teoria Literária: 157-82.

https://periodicos.ufpe.br/revistas/INV/article/view/1443

Recebido: 10/9/2020

Versão revista e corrigida: 5/11/2020

Aceito: $9 / 11 / 2020$

Publicado: 11/11/2020

LIAMES, Campinas, SP, v. 20, 1-17, e020017, 2020 